\title{
Evidence for degradation of 2-chlorophenol by enrichment cultures under denitrifying conditions
}

\author{
Hee-Sung Bae,† Takao Yamagishi and Yuichi Suwa
}

National Institute of Advanced Industrial Science and Technology (AIST), 16-1 Onogawa, Tsukuba, Ibaraki 305-8569, Japan
Author for correspondence: Yuichi Suwa. Tel: +81298 61 8747. Fax: +81298618309. e-mail: y-suwa@aist.go.jp

\begin{abstract}
Although chlorophenol (CP) degradation has been studied, no bacterium responsible for degradation of CP under denitrifying conditions has been isolated. Moreover, little substantial evidence for anaerobic degradation of CPs coupled with denitrification is available even for mixed cultures. Degradation of CP [2-CP, 3-CP, 4-CP, 2,4-dichlorophenol (DCP) or 2,6-DCP] under denitrifying conditions was examined in anaerobic batch culture inoculated with activated sludge. Although 3-CP, 4-CP, 2,4-DCP and 2,6-DCP were not stably degraded, 2$\mathrm{CP}$ was degraded and its degradation capability was sustained in a subculture. However, the rate of 2-CP degradation was not significantly enhanced by subculturing. In 2-CP-degrading cultures, nitrate was consumed stoichiometrically and concomitantly during 2-CP degradation, and a dechlorination intermediate was not detected, suggesting that 2-CP degradation was coupled with nitrate reduction. A 2-CP-degrading enrichment culture degraded 2-CP in the presence of nitrate, but did not in the absence of nitrate or the presence of sulfate. This suggests that the enrichment culture strictly requires nitrate for degradation of 2-CP. The apparent specific growth rate of the 2-CP degrading species was $0.0139 \mathrm{~d}^{-1}$. Thus the apparent doubling time of the 2-CP-degrading population in the enrichment culture was greater than $50 \mathrm{~d}$, which may explain difficulty in enrichment and isolation of microorganisms responsible for $\mathrm{CP}$ degradation under denitrifying conditions.
\end{abstract}

Keywords: anaerobic degradation, chlorophenols, denitrification, enrichment culture

\section{INTRODUCTION}

Anaerobic processes are beneficial for eliminating pollutants from contaminated sites, in which oxygen is often unavailable due to its quick depletion with easily utilizable substrates, low solubility in water and low rate of transportation in saturated porous matrices such as soils and sediments. Denitrifying bacteria, which are basically categorized as aerobes, have received attention because they could be active under anoxic conditions. Their facultative trait allows them to have a more extensive range of habitats with different oxygen concentrations than other microbial groups. Moreover, their potential to degrade hazardous pollutants such as

\footnotetext{
†Present address: Biosystem Engineering Laboratory, Department of Chemical Engineering, Korean Advanced Institute for Science and Technology, 373-1 Kusong-Dong, Yusung-Gu, Taejon 305-701, Korea.

Abbreviations: CP, chlorophenol; DCP, dichlorophenol.
}

aromatic hydrocarbons, phenols and benzoate derivatives has been reported (Braun \& Gibson, 1984; Nozawa \& Maruyama, 1988; Dolfing et al., 1990; Fries et al., 1994; Frazer et al., 1995; Rabus \& Widdel, 1995; Heider \& Fuchs, 1997; van Schie \& Young, 1998; Rockne et al., 2000). Thus, it has sometimes been considered that denitrifying processes would be an alternative clean-up strategy in sites contaminated with pollutants.

Chlorophenols (CPs) are common environmental pollutants arising from the extensive use of wood preservatives, herbicides and fungicides (Valo et al., 1985), and are also found in pulp bleaching effluents and industrial wastewater (Kringstad \& Lindström, 1984; Valo et al., 1984). Anaerobic degradation of CPs has mainly been studied under methanogenic conditions in anaerobic sediments (Zhang \& Wiegel, 1990) with microbial consortia obtained from various environments (Boyd \& Shelton, 1984; Gibson \& Suflita, 1986; Mikesell \& Boyd, 1986; Genthner et al., 1989a ; Madsen \& Aamand, 1992; 
Mohn \& Kennedy, 1992; Nicholson et al., 1992; Takeuchi et al., 2000) and anaerobic reactor systems (Woods et al., 1989; Juteau et al., 1995). These studies have indicated that CPs are initially dechlorinated to less chlorinated phenols via a reductive dechlorination, and, then, ultimately mineralization to methane and $\mathrm{CO}_{2}$ in some cases. Recently, some anaerobic bacteria capable of aryl-dechlorination have been obtained from methanogenic enrichments (Madsen \& Licht, 1992; Cole et al., 1994; Utkin et al., 1995; Sanford et al., 1996). A few studies have been conducted to investigate the anaerobic degradation of chloroaromatics under reducing conditions other than methanogenic conditions such as denitrifying conditions, sulfate-reducing conditions and iron reducing conditions (Genthner et al., 1989b; Häggblom \& Young, 1990, 1995; Häggblom et al., 1993; Kazumi et al., 1995). These studies established sulfate- and iron-reducing enrichments capable of degrading $\mathrm{CPs}$, and demonstrated that the anaerobic degradation of CPs was coupled with sulfate reduction (Genthner et al., 1989b; Häggblom \& Young, 1990, 1995; Häggblom et al., 1993) or iron reduction (Kazumi et al., 1995). Anaerobic degradation of 2-CP was observed in a sediment or a water sample incubated with nitrate (Genthner et al., 1989b; Häggblom et al., 1993), but the capability could not be sustained by re-feeding with 2-CP or by transferring the sample culture to fresh medium. Thus, there has been no substantial evidence for anaerobic degradation of CPs coupled with denitrification; thereby CPs have been regarded as recalcitrant under denitrifying conditions until now. Obtaining evidence of CP degradation under denitrifying conditions was the aim of this study. First, we attempted to establish enrichment cultures with sustained capability to degrade CPs under denitrifying conditions. Second, the kinetics and physiological characteristics of the enrichment cultures were quantitatively evaluated with respect to CP degradation under denitrifying conditions.

\section{METHODS}

Sludge samples. Five activated sludge samples were collected from different wastewater treatment plants. To deplete indigenous carbons, an aliquot $(0.5 \mathrm{~g}$ dry wt) of sludge sample was incubated in a tightly sealed $68 \mathrm{ml}$ serum bottle containing $50 \mathrm{ml}$ mineral salt medium (MSM) with $5 \mathrm{mM}$ nitrate at $25^{\circ} \mathrm{C}$. After 1 week incubation, the supernatant was discarded after centrifugation and a freshly prepared medium of the same composition was added to the precipitate. This procedure was performed twice. All the biomass in the bottle was harvested by centrifugation (7000 $\mathrm{g}$ for $10 \mathrm{~min}$ ) and used as an inoculum for enrichment cultures. The harvested biomass was transferred into an anaerobic chamber (COY), in which anaerobic handling was conducted, and suspended in a fresh medium anaerobically prepared as described below. The anaerobic chamber was filled with a gas mixture of $80 \%$ $\mathrm{N}_{2} / 10 \% \mathrm{CO}_{2} / 10 \% \mathrm{H}_{2}$.

Media. The culture medium was prepared by strictly anaerobic techniques and used throughout the study. The MSM used in this study was composed of $2 \mathrm{~g} \mathrm{Na}_{2} \mathrm{HPO}_{4}, 1 \cdot 0 \mathrm{~g} \mathrm{KH}_{2} \mathrm{PO}_{4}, 0.5 \mathrm{~g}$ $\mathrm{NH}_{4} \mathrm{Cl}$ and $0-0.43 \mathrm{~g} \mathrm{NaNO}_{3}$ in $1 \mathrm{l}$ distilled water. After autoclaving, the medium in the reservoir was quickly chilled with running water under flushing $\mathrm{N}_{2}$ that is passed through an oxygen-trap filter (Chemical Research Supplies), and then $1 \mathrm{ml}$ EDTA-chelated trace element mixture, $1 \mathrm{ml}$ alkalineearth-metal solution $\left(100 \mathrm{~g} \mathrm{MgCl}_{2} \cdot 6 \mathrm{H}_{2} \mathrm{O}, 25 \mathrm{~g} \mathrm{CaCl}_{2} \cdot 2 \mathrm{H}_{2} \mathrm{O}\right.$ in 11 distilled water), $1 \mathrm{ml} \mathrm{Na} 2 \mathrm{SeO}_{3} / \mathrm{Na}_{2} \mathrm{WO}_{4}$ solution (Widdel \& Bak, 1992), vitamin solutions (Widdel \& Bak, 1992) and $5 \mathrm{ml}$ bicarbonate solution $\left(84 \mathrm{~g} \mathrm{NaHCO}_{3}\right.$ in 11 distilled water) were added to $11 \mathrm{MSM}$ in an anaerobic chamber. The trace element solution was composed of $5.2 \mathrm{~g}$ EDTA, $0.45 \mathrm{~g} \mathrm{FeCl}_{2} \cdot 4 \mathrm{H}_{2} \mathrm{O}, 52 \mathrm{mg} \mathrm{ZnCl}_{2}, 0 \cdot 19 \mathrm{~g} \mathrm{CoCl}_{2} \cdot 6 \mathrm{H}_{2} \mathrm{O}, 0 \cdot 1 \mathrm{~g}$ $\mathrm{MnSO}_{4} \cdot 5 \mathrm{H}_{2} \mathrm{O}, 24 \mathrm{mg} \mathrm{NiCl} 2.6 \mathrm{H}_{2} \mathrm{O}, 29 \mathrm{mg} \mathrm{CuCl}{ }_{2} .2 \mathrm{H}_{2} \mathrm{O}, 36 \mathrm{mg}$ $\mathrm{Na}_{2} \mathrm{MoO}_{4} \cdot 2 \mathrm{H}_{2} \mathrm{O}$ and $30 \mathrm{mg} \mathrm{H}_{3} \mathrm{BO}_{3}$ in 11 distilled water. As a reducing agent, $\mathrm{Na}_{2} \mathrm{~S} .9 \mathrm{H}_{2} \mathrm{O}$ was added to the medium as a stock solution $(0.2 \mathrm{M})$ to a final concentration of $0.2 \mathrm{mM}$. The $\mathrm{pH}$ of the media was adjusted to $7 \cdot 2$. The stock solutions $(0.5 \mathrm{M})$ of CPs were prepared by dissolving them in $0.2 \mathrm{M}$ $\mathrm{NaOH}$.

Enrichment culture. An aliquot of the sludge biomass $(20 \mathrm{mg}$ dry wt), pre-treated as mentioned above, was transferred to a $68 \mathrm{ml}$ serum bottle containing $50 \mathrm{ml} \mathrm{MSM}$ with $5 \mathrm{mM}$ nitrate in an anaerobic chamber. The bottle was tightly sealed with a butyl rubber stopper and an aluminium seal before exposure to ambient air. Thus, the resultant headspace of the bottle was nominally the same as that of the anaerobic chamber. A filtersterilized stock solution of either 2-CP, 3-CP, 4-CP, 2,4dichlorophenol (DCP) or 2,6-DCP was injected using a syringe through the butyl rubber stopper to provide a final concentration of $0 \cdot 1 \mathrm{mM}$ in the anaerobic chamber. To avoid oxygen contamination during the withdrawal of culture samples, the headspaces of the bottles were kept under positive pressure by an additional supply of oxygen-free nitrogen up to 20-30 KPa. All cultures were incubated in the dark at $25^{\circ} \mathrm{C}$. When all the CP supplied to the bottle was degraded, $10 \mathrm{ml}$ of the CP-degrading culture in the bottle was transferred into $68 \mathrm{ml}$ bottles containing $40 \mathrm{ml}$ freshly prepared MSM with $5 \mathrm{mM}$ nitrate. The same CP species was added to bottles inoculated with a CP-degrading culture to a final concentration of $0 \cdot 1 \mathrm{mM}$, and no CP was added to the other bottles to serve as a control.

Degradation of 2-CP under other anaerobic conditions. Biomass from the enrichment culture that degraded 2-CP in the once-transferred cultures was collected by centrifugation (7000 $\mathrm{g}$ for $10 \mathrm{~min}$ ) from a bottle containing $50 \mathrm{ml}$ culture broth and washed three times with nitrate-free MSM to remove nitrate. The washed biomass pellet was placed in the anaerobic chamber and suspended in nitrate-free MSM. Fifty millilitres of the biomass suspension was transferred to each of six $68 \mathrm{ml}$ serum bottles and 2-CP added to a final concentration of $70 \mu \mathrm{M}$. Of the six bottles, two were anaerobically spiked with nitrate $(5 \mathrm{mM})$, two with sulfate $(5 \mathrm{mM})$ and the remaining two with neither nitrate nor sulfate.

Analytical procedures. During incubation, $1 \mathrm{ml}$ of each culture fluid was anaerobically collected several times using a syringe injected through a butyl rubber stopper. Sampling was carried out in the anaerobic chamber. Samples were filtered through a PVDF $0.22 \mu \mathrm{m}$ pore-size Millipore filter and stored at $-20^{\circ} \mathrm{C}$ until use. CPs were analysed using a high-performance liquid chromatograph (Hewlett Packard) equipped with a C-18 column and a diode-array detector for monitoring substances at $280 \mathrm{~nm}$. A mixture of water/methanol/acetic acid (40:60:1, by vol.) was used as a running buffer for HPLC analysis, the flow rate of which was $1 \mathrm{ml} \mathrm{min}^{-1}$. Nitrate and nitrite were analysed using an ion chromatograph (IC7000, Yokogawa) equipped with a conductivity detector and an anion exchange column, with $3 \mathrm{mM}$ sodium bicarbonate 


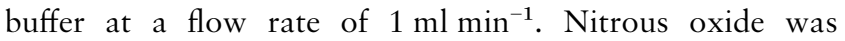
quantitatively sampled using a gas-tight syringe and analysed using a gas chromatograph (HP5890, Hewlett Packard) equipped with ECD and $3 \mathrm{~m}$ stainless-steel column $(3.2 \mathrm{~mm}$ external diameter) packed with Porapak Q50/80. A gas mixture comprising $95 \%$ argon and $5 \%$ methane was used as the carrier gas, the flow rate of which was $30 \mathrm{ml} \mathrm{min}^{-1}$.

\section{RESULTS AND DISCUSSION}

\section{Sustained 2-CP degradation capability under denitrifying conditions}

The activated sludge samples collected from five different wastewater treatment plants were anaerobically incubated with nitrate and one of the CPs 2-CP, 3-CP, 4CP, 2,4-DCP or 2,6-DCP. Of the five CPs examined in this study using five sludge samples, 2-CP and 3-CP were degraded in $207 \mathrm{~d}$, but the others (4-CP, 2,4-DCP and 2,6-DCP) were not. As shown in Table 1, 3-CP was degraded faster, but by fewer sample cultures than 2-CP. It appears that the number of substituted chlorine molecules on an aromatic ring, as well as their positions, could be factors affecting CP degradation under the given conditions. All the activated sludge samples tested degraded monochlorophenols, but not DCPs. Among the monochlorophenols used, 2-CP was susceptible to degradation by the largest number of samples while 3$\mathrm{CP}$ was most quickly degraded by two samples.

CP-degrading cultures were transferred to a freshly prepared medium of the same composition in terms of the added CPs, and incubated under denitrifying conditions. In the once-transferred cultures (first subculture), the capability of 2-CP degradation by the four en- richment cultures originally inoculated with sludges B, C, D or E was successfully retained (Table 1 ). Further, 2$\mathrm{CP}$ degradation was also observed in two of the four enrichment cultures (originally inoculated with sludges $\mathrm{B}$ and $\mathrm{C}$ ) when they were transferred for a second time (second subculture) (Table 1). On the other hand, with the transfer of two 3-CP-degrading cultures to a freshly prepared medium, their 3-CP degradation capability was not retained.

During the degradation of 2-CP in original and transferred cultures, no UV-absorbable intermediates such as phenol or benzoate were detected by HPLC analysis. This suggests that 2-CP degradation in our enrichment cultures is distinguished from transformation of CPs to less- or non-chlorinated phenol via a reductive dechlorination usually observed under methanogenic conditions. To our knowledge, it has rarely been observed that a microbial enrichment culture capable of degrading $\mathrm{CP}$ is sustained under denitrifying conditions, which has limited the microbiological study of this subject. Thus, these 2-CP-degrading cultures obtained here may be good materials for further work on this subject.

\section{Stoichiometry of 2-CP degradation and nitrate reduction}

Fig. 1(a) shows that the 2-CP-degrading culture originally inoculated with sludge $\mathrm{C}$, which was transferred twice to a freshly prepared medium (second subculture), degraded 0.1 mM 2-CP in 168 d. As shown in Fig. 1(b), nitrate was consumed concomitantly during 2-CP degradation, and nitrite transiently accumulated. Another intermediate in the denitrification pathway, nitrous

Table 1. Anaerobic degradation of CPs by primary and transferred cultures under denitrifying conditions

NT, Not tested.

\begin{tabular}{|lcccc|}
\hline Substrate* & $\begin{array}{c}\text { Sludge used for } \\
\text { inoculum }\end{array}$ & \multicolumn{2}{c|}{ Time required for degrading $\mathbf{0} \cdot \mathbf{1} \mathbf{m M ~ C P}(\mathbf{d}) \dagger$} \\
\cline { 2 - 5 } & & $\begin{array}{c}\text { Original } \\
\text { enrichment }\end{array}$ & $\begin{array}{c}\text { First } \\
\text { subculture } \neq\end{array}$ & $\begin{array}{c}\text { Second } \\
\text { subculture } \ddagger\end{array}$ \\
\hline $2-\mathrm{CP}$ & $\mathrm{B}$ & $88-105(2 / 2)$ & $56-94(8 / 8)$ & $202(2 / 2)$ \\
& $\mathrm{C}$ & $88-105(2 / 2)$ & $56-148(8 / 8)$ & $168-214(7 / 7)$ \\
& $\mathrm{D}$ & $88-207(2 / 2)$ & $78-375(7 / 7)$ & $\mathrm{NTS}$ \\
$3-\mathrm{CP}$ & $\mathrm{E}$ & $68-207(2 / 2)$ & $56-327(6 / 7)$ & $\mathrm{NT}$ \\
& $\mathrm{A}$ & $17(1 / 2)$ & $(0 / 4) \|$ & $\mathrm{NT}$ \\
& $\mathrm{D}$ & $17(1 / 2)$ & $11(1 / 4)$ & $(0 / 4) \mathbf{9}$ \\
\hline
\end{tabular}

* Only CP species which were degraded in this study are listed.

†No. positive cultures/total no. replicate cultures is shown in parentheses.

¥ When CP added was completely degraded, $10 \mathrm{ml}$ enrichment was transferred into $40 \mathrm{ml}$ fresh medium and then CP $(0 \cdot 1 \mathrm{mM})$ was added.

$\$$ Replicates of first subculture were not transferred.

|| No degradation was found in $428 \mathrm{~d}$.

9 No degradation was found in $395 \mathrm{~d}$. 

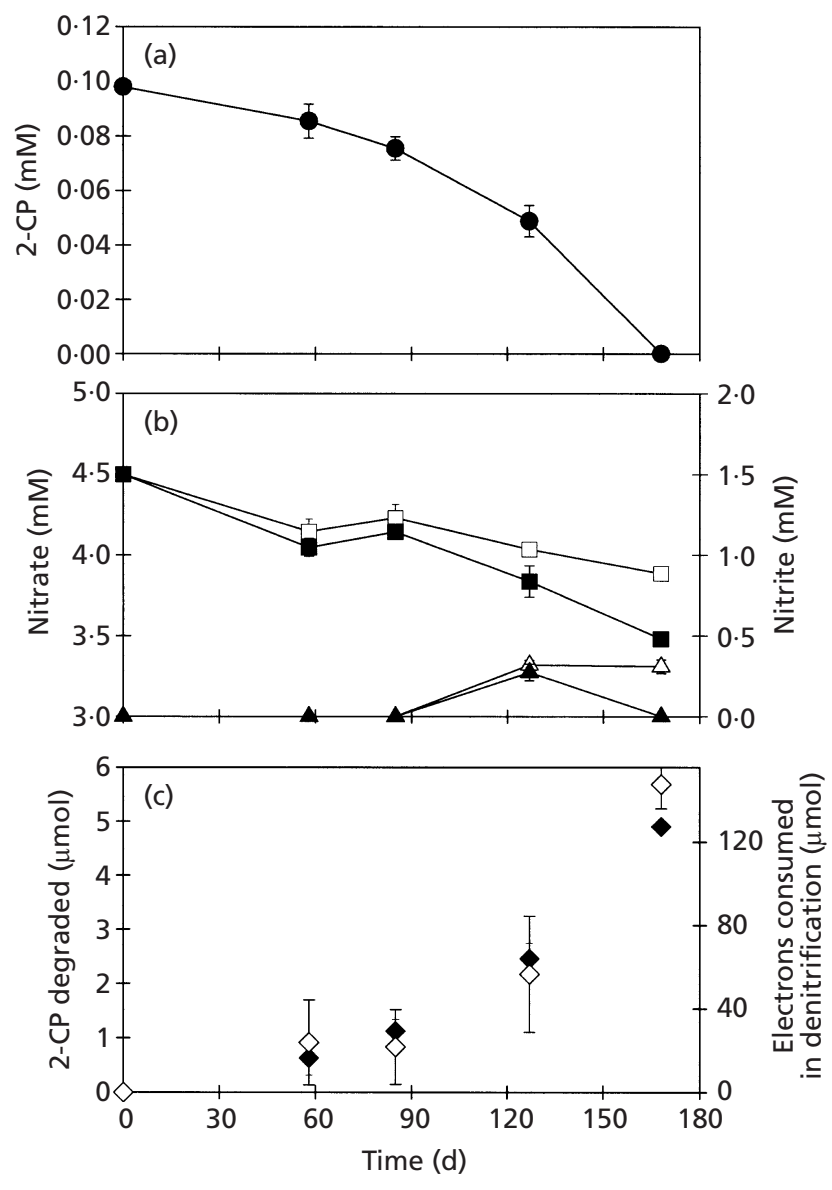

Fig. 1. Degradation of $2-\mathrm{CP}$ and consumption of nitrate in the second subculture derived from activated sludge C. Symbols: 2$\mathrm{CP}(\boldsymbol{O})$, nitrate $(\boldsymbol{\square}, \square)$ and nitrite $(\boldsymbol{\Delta}, \triangle)$ in the presence $(\boldsymbol{\square}$, $\Delta)$ and the absence $(\square, \triangle)$ of 2-CP; electrons consumed via nitrate reduction $(\diamond) ; 2-\mathrm{CP}$ degraded $(\diamond)$. Error bars represent standard deviations from triplicate (with 2-CP) and duplicate (without 2-CP) cultures.

oxide, was also detected in test cultures to which 2-CP was added (Table 2). It is notable that the calculated number of electrons consumed via denitrification appeared to be stoichiometric to 2-CP degradation all the way through the experiment (Fig. 1c). Nitrate cannot be assimilated as it is but should be reduced to ammonia before assimilation. Thus, the growing population of bacterial cells in a 2-CP-degrading culture would preferentially assimilate the ammonia $(10 \mathrm{mM})$ added to the media. Rice \& Tiedje (1989) demonstrated that ammonium salts contained in the medium at a high concentration inhibited assimilatory nitrate reduction. Therefore it is more likely that nitrate would be consumed during denitrification than during assimilation. Even though nitrate was used for assimilation of cellular materials, its level is much lower than that used as an electron acceptor in the degradation of 2-CP. Assuming all of the 2-CP $(5 \mu \mathrm{mol})$ and nitrate could each be solely assimilated into the cell biomass composed of $\mathrm{C}_{5} \mathrm{H}_{7} \mathrm{O}_{2} \mathrm{~N}$ (Hoover \& Porges, 1952), $6 \mu \mathrm{mol}$ nitrate could be consumed. The actual observed amount of nitrate consumed by each 2-CP-degrading culture (Table 2) was much larger than this value. Thus, the amount of nitrate consumed was not explained in terms of assimilation, but in terms of another mechanism, i.e. denitrification.

Table 2 shows that $23.5-41.5 \mu \mathrm{mol}$ nitrate was consumed, although 2-CP was not added to the cultivation vials, and significantly transformed to denitrification intermediates, such as nitrite $(50 \cdot 3-95 \cdot 7 \%)$ and nitrous oxide $(0 \cdot 4-8 \cdot 8 \%)$. Cultures to which $2-\mathrm{CP}$ was added consumed more nitrate; however, percentages of denitrification intermediates formed from nitrate, such as nitrite $(0 \%)$ and nitrous oxide $(0 \cdot 4-10 \cdot 5 \%)$, were much smaller than those found in vials to which 2-CP was not added. These results indicate that each enrichment culture has an endogenous denitrification activity that was apparently enhanced by the addition of 2-CP. The number of electrons consumed via nitrate reduction was calculated for each culture using the amount of consumed nitrate and accumulated intermediates (nitrite and nitrous oxide) after the 2-CP was completely degraded (Table 2). In the calculation, it was presumed that nitrate was completely consumed via dissimilatory denitrification.

Regarding results obtained for a 2-CP-degrading denitrifying culture originally inoculated with sludge $C$, it was estimated that a mean of $143.8 \mu \mathrm{mol}$ electrons was consumed by denitrification (Table 2). The theoretical amount of electrons produced via 2-CP oxidation was also calculated for each 2-CP degrading culture under denitrifying conditions (Table 2). In theory, complete oxidation of $1 \mu \mathrm{mol} 2$-CP would provide $26 \mu \mathrm{mol}$ electrons. For the 2-CP-degrading culture originally inoculated with sludge C, $127 \cdot 4 \mu \mathrm{mol}$ electrons would theoretically be produced from $4.9 \mu \mathrm{mol} 2-\mathrm{CP}$ consumed, which is similar to the estimated amount of electrons consumed $(143.8 \mu \mathrm{mol})$. As shown in Table 2, the amount of electrons consumed via dissimilatory nitrate reduction was similar to that theoretically produced by 2-CP degradation for other cultures, suggesting that nitrate reduction was apparently accompanied by 2-CP degradation. Other previous studies showed anaerobic degradation of 2-CP in denitrifying enrichment cultures (Genthner et al., 1989b; Häggblom et al., 1993), however, these studies did not demonstrate the consumption of nitrate during degradation of 2-CP, which may suggest that the substrate used was coupled to denitrification. The present study would provide information on this aspect.

\section{Apparent specific growth rate of micro-organisms responsible for 2-CP degradation}

The shape of the 2-CP degradation curve shown in Fig. 1 (a) indicates that the 2-CP degradation rate increased with incubation time, possibly as a result of growth of micro-organisms responsible for 2-CP degradation and/or release from substrate inhibition. The experimentally obtained time course data for 2-CP degradation by the enrichment culture originally inoculated 
Table 2. Estimation of electrons consumed by denitrification in denitrifying 2-CP-degrading consortia, and theoretical amount of electrons produced from 2-CP degradation

Data used were obtained from first subcultures in inocula D and E, and second subcultures in inocula B and C. All parameters were obtained after 2-CP was completely degraded.

\begin{tabular}{|c|c|c|c|c|c|c|c|c|c|c|}
\hline \multirow[t]{2}{*}{$\begin{array}{l}\text { Sludge used } \\
\text { for inoculum }\end{array}$} & \multirow[t]{2}{*}{$\begin{array}{l}\text { 2-CP added } \\
(\mu \mathrm{mol})\end{array}$} & \multirow[t]{2}{*}{$\begin{array}{l}\text { No. } \\
\text { replicates }\end{array}$} & \multirow[t]{2}{*}{$\begin{array}{l}\text { 2-CP degraded } \\
(\mu \mathrm{mol})\end{array}$} & \multirow[t]{2}{*}{$\begin{array}{c}\text { Nitrate } \\
\text { consumed }(\mu \mathrm{mol})\end{array}$} & \multirow[t]{2}{*}{$\begin{array}{c}\text { Nitrite } \\
\text { produced }(\mu \mathrm{mol})\end{array}$} & \multirow[t]{2}{*}{$\begin{array}{c}\text { Nitrous oxide } \\
\text { produced }(\mu \mathrm{mol})\end{array}$} & \multirow{2}{*}{$\begin{array}{c}\text { Electrons } \\
\text { theoretically } \\
\text { produced from } \\
2-\mathrm{CP}(\mu \mathrm{mol})^{*}\end{array}$} & \multicolumn{2}{|c|}{$\begin{array}{l}\text { Electrons consumed by nitrate } \\
\text { reduction }(\mu \mathrm{mol}) \dagger\end{array}$} & \multirow{2}{*}{$\begin{array}{c}\text { Electrons } \\
\text { consumed/produced } \\
(\%)\end{array}$} \\
\hline & & & & & & & & Overall & Net‡ & \\
\hline \multirow[t]{2}{*}{ B } & $20 \cdot 5 \mathbb{S}$ & 2 & $20 \cdot 5$ & $147 \cdot 0 \pm 67 \cdot 2$ & 0 & $15 \cdot 47 \pm 0 \cdot 1$ & 533.0 & $727 \cdot 3 \pm 403 \cdot 0$ & $654 \cdot 4$ & $122 \cdot 7$ \\
\hline & None & 1 & None & $23 \cdot 5$ & $22 \cdot 5$ & $0 \cdot 1$ & None & $72 \cdot 9$ & 0 & 0 \\
\hline \multirow[t]{2}{*}{ C } & $4 \cdot 9$ & 3 & $4 \cdot 9$ & $51 \cdot 0$ & 0 & $2 \cdot 9 \pm 0 \cdot 1$ & $127 \cdot 4$ & $249 \cdot 3 \pm 11$ & $143 \cdot 8$ & $112 \cdot 8$ \\
\hline & None & 2 & None & $30 \cdot 8 \pm 0 \cdot 4$ & $15 \cdot 5 \pm 2 \cdot 1$ & $0 \cdot 9 \pm 0$ & None & $105 \cdot 5 \pm 8 \cdot 1$ & 0 & 0 \\
\hline \multirow[t]{2}{*}{ D } & $5 \cdot 0$ & 3 & $5 \cdot 0$ & $56 \cdot 3 \pm 5 \cdot 3$ & 0 & $0 \cdot 2 \pm 0 \cdot 2$ & $130 \cdot 0$ & $281 \cdot 2 \pm 26 \cdot 9$ & $143 \cdot 6$ & $110 \cdot 5$ \\
\hline & None & 1 & None & $41 \cdot 5$ & $22 \cdot 0$ & $1 \cdot 94$ & None & $137 \cdot 6$ & 0 & 0 \\
\hline \multirow[t]{2}{*}{$\mathrm{E}$} & $4 \cdot 8$ & 2 & $4 \cdot 8$ & $53 \cdot 5 \pm 2 \cdot 1$ & 0 & $3 \cdot 2 \pm 1 \cdot 0$ & $125 \cdot 8$ & $256 \cdot 1 \pm 12 \cdot 7$ & $158 \cdot 5$ & $126 \cdot 1$ \\
\hline & None & 1 & None & $41 \cdot 0$ & $34 \cdot 0$ & $0 \cdot 2$ & None & $102 \cdot 5$ & 0 & 0 \\
\hline
\end{tabular}

* Amounts of electrons produced from 2-CP were calculated by assuming complete oxidation of 2-CP to $\mathrm{CO}_{2}$. One micromole of 2-CP presumably provides $26 \mu \mathrm{mol}$ electrons.

† Values were calculated as: $\left(\mathrm{NO}_{3}^{-}\right.$consumed $-\mathrm{NO}_{2}^{-}$accumulated $-2 \times \mathrm{N}_{2} \mathrm{O}$ accumulated $) \times 5+\left(\mathrm{NO}_{2}^{-}\right.$accumulated $) \times 2+\mathrm{N}_{2} \mathrm{O}$ accumulated) $\times 8$.

‡ Values were calculated as (overall electrons consumed by nitrate reduction with 2-CP)-(overall electrons consumed by nitrate reduction without $2-\mathrm{CP})$.

$\mathbb{S}$ When $5 \mu \mathrm{mol} 2$-CP was completely degraded, $15 \mu \mathrm{mol} 2$-CP was additionally supplied to the culture.

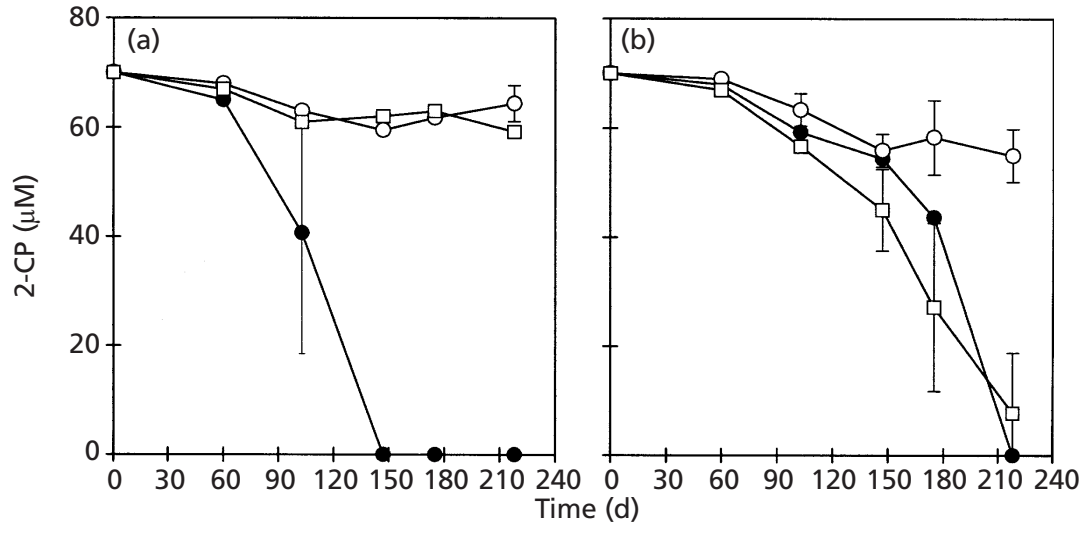

Fig. 2. Anaerobic degradation of $2-\mathrm{CP}$ by a microbial consortium inoculated with sludge $\mathrm{E}(\mathrm{a})$, and with sludge $\mathrm{D}(\mathrm{b})$ with nitrate $(\mathbf{Q})$ or sulfate $(\bigcirc)$, or without nitrate or sulfate $(\square)$. Bars represent the standard deviation from duplicate cultures. with sludge $\mathrm{C}$ could be fitted with equation 1 , which assumes exponential growth of 2-CP-degrading microbial population:

$\left(S_{\mathrm{o}}-S\right)=k\left(\mathrm{e}^{\mu t}-1\right)$

where $S_{0}$ is the initial substrate concentration, $S$ is the substrate concentration at the incubation time period $t$, $k$ is the initial 2-CP degradation rate at time 0 and $\mu$ is the specific growth rate of micro-organisms responsible for 2-CP degradation. It is notable that the apparent specific growth rate of the 2-CP-degrading microbial population was extremely slow, $0 \cdot 0139 \mathrm{~d}^{-1}$, representing an apparent doubling time of $50 \cdot 2 \mathrm{~d}$ for the population. This result indicates that the 2-CP degrading microbial population has substantially multiplied no more than three times by incubating the enrichment culture for $150 \mathrm{~d}$, which increased the biomass of micro-organisms responsible for 2-CP degradation by only eight times. This may explain why the incubation period required for degrading $0 \cdot 1 \mathrm{mM} 2-\mathrm{CP}$ was not reduced when $20 \%$ of the culture was transferred to a freshly prepared medium (Table 1). Thus, a longer incubation of subcultures would be required to obtain an enrichment culture adequate for isolating the putative 2-CP-degrading organisms, and further microbiological studies on this subject would be difficult because of such a slow rate of 2-CP degradation.

\section{Degradation of 2-CP under other anaerobic conditions}

To examine whether 2-CP utilizing enrichment cultures degrade 2-CP under other anaerobic conditions, four first subcultures originally inoculated with sludges B, C, $\mathrm{D}$ and $\mathrm{E}$ were incubated in an anaerobically prepared medium with nitrate $(5 \mathrm{mM})$ or sulfate $(5 \mathrm{mM})$, or without nitrate or sulfate. The culture originally inoculated with sludge $\mathrm{E}$ demonstrated that 2-CP was degraded in the presence of nitrate in $147 \mathrm{~d}$, but was not degraded under other conditions (Fig. 2a). This indicates 
that the enrichment culture required nitrate for anaerobic degradation of 2-CP. Based on this result and the stoichiometry of 2-CP degradation and nitrate consumption (Table 2), it is likely that the anaerobic degradation of 2-CP in this enrichment culture was strictly dependent on denitrification.

Sanford \& Tiedje (1997) reported a degradation pathway of 2-CP in anaerobic microcosms supplemented with nitrate. They demonstrated that 2-CP was transformed to phenol by a reductive dechlorination, and the resulting phenol was subsequently degraded coupled with denitrification. They observed that dechlorination was inhibited by $5 \mathrm{mM}$ or higher nitrate, and the reaction proceeded without nitrate. On the other hand, we have observed 2-CP degradation in the presence of $5 \mathrm{mM}$ nitrate, and no accumulation of dechlorination intermediates in enrichment cultures. Furthermore, 2$\mathrm{CP}$ degradation and putative electron consumption via denitrification proceeded concomitantly and stoichiometrically (Fig. 1), unlike Sanford \& Tiedje (1997) observed. Thus, it is unclear that reductive dechlorination activity was involved in the degradation of 2-CP in our enrichment culture especially derived from sludges $\mathrm{C}$ and $\mathrm{E}$, and it appears that the mechanism of 2-CP degradation which we observed in this study could be different from what Sanford \& Tiedje (1997) observed. These observations suggest the presence of a denitrifying population capable of degrading $\mathrm{CP}$ by a mechanism not involving reductive dechlorination. As for enriching conditions, ours retained nitrate during incubation, but theirs did not and was in a more reduced condition during most of the incubation period. Thus, denitrifying conditions may have been well maintained in our samples.

The culture originally inoculated with sludge $\mathrm{D}$ degraded 2-CP in the absence of nitrate or sulfate and in the presence of nitrate (Fig. 2b). However, this culture did not degrade 2-CP in the presence of sulfate (Fig. 2b). When $62 \mu \mathrm{M} 2-\mathrm{CP}$ was degraded in the absence of an electron acceptor, $59 \mu \mathrm{M}$ phenol was detected, indicating that 2-CP was reductively dechlorinated. One possible explanation for the observation is that this enrichment culture may have retained two pathways for anaerobic degradation of 2-CP: one dependent on denitrification and the other independent of it. Further examination would be necessary to clarify whether the reductive dechlorination, which is basically a denitrification-independent pathway, occurs in the presence of nitrate. However, since phenol was not detected in the culture supplied with nitrate, it is not really evident whether the enrichment culture in the bottle concomitantly underwent two reactions, reductive dechlorination and denitrifying degradation of 2-CP.

Cultures originally inoculated with sludges B and C did not degrade 2-CP in the presence of nitrate or sulfate or in the absence of exogenous electron acceptors (data not shown), although these cultures successfully degraded 2$\mathrm{CP}$ when they were transferred into a fresh medium with nitrate without washing as described in Table 1. The reason why 2-CP was not degraded even in the nitrateadded medium is unclear, but one possible explanation may be the inadequate preparation of the inocula. The sludge samples used as inocula were aerobically washed three times with a nitrate-free medium. This procedure may have unintentionally damaged the degradation capability of the micro-organisms or discharged factors required for degradation.

\section{Conclusion}

We have demonstrated that denitrifying conditions supported an anaerobic degradation of CPs in enrichment cultures derived from activated sludge samples. Concomitant consumption of nitrate was observed during 2-CP degradation, the amount of which was stoichiometric, assuming that 1) 2-CP was completely oxidized to $\mathrm{CO}_{2}$ and 2) nitrate was solely consumed as an electron acceptor in denitrification (Fig. 1 and Table 2 ). This would be evidence demonstrating that 2-CP degradation is coupled to respiratory denitrification. The strict requirement of nitrate for degradation of 2$\mathrm{CP}$ was observed in a 2-CP-degrading enrichment culture under denitrifying conditions (Fig. 2a), which provides support for the involvement of the denitrification process in anaerobic degradation of 2-CP. Although the 2-CP-degrading enrichment cultures under denitrifying conditions were subcultured repeatedly, the degradation rate could not significantly be increased, possibly because the apparent growth rate of the 2-CPdegrading microbial population was extremely slow, the apparent doubling time of which was $50 \cdot 2 \mathrm{~d}$. The degradation capability of the culture once enriched was easily lost, particularly when the biomass of the enrichment culture was washed under aerobic conditions. Thus, we do not yet know the conditions for properly and stably maintaining a 2-CP-degrading enrichment culture under denitrifying conditions. Studies are still needed to determine the contribution of the denitrification process in the anaerobic degradation of CPs in contaminated environments, however, the extremely slow degradation rate may imply that this process could easily be predominated by other anaerobic processes.

\section{ACKNOWLEDGEMENTS}

We thank Dr K. Yoshida of National Institute of Advanced Industrial Science and Technology for his kind help in the kinetic data analysis.

\section{REFERENCES}

Boyd, S. A. \& Shelton, D. R. (1984). Anaerobic biodegradation of chlorophenols in fresh and acclimated sludge. Appl Environ Microbiol 47, 272-277.

Braun, K. \& Gibson, D. T. (1984). Anaerobic degradation of 2aminobenzoate (anthranilic acid) by denitrifying bacteria. Appl Environ Microbiol 48, 102-107.

Cole, J. R., Cascarelli, A. L., Mohn, W. W. \& Tiedje, J. M. (1994). Isolation and characterization of a novel bacterium growing via reductive dehalogenation of 2-chlorophenol. Appl Environ Microbiol 60, 3536-3542. 
Dolfing, J., Zeyer, J., Binder-Eicher, P. \& Schwarzenbach, R. P. (1990). Isolation and characterization of a bacterium that mineralizes toluene in the absence of molecular oxygen. Arch Microbiol 154, 336-341.

Frazer, A. C., Coschigano, P. W. \& Young, L. Y. (1995). Toluene metabolism under anaerobic conditions: a review. Anaerobe 1, 293-303.

Fries, M. R., Zhou, J., Chee-Sanford, J. \& Tiedje, J. M. (1994). Isolation, characterization, and distribution of denitrifying toluene degraders from a variety of habitats. Appl Environ Microbiol 60, 2802-2810.

Genthner, B. R. S., Price, W. A., II \& Prichard, P. H. (1989a). Characterization of anaerobic dechlorinating consortia derived from aquatic sediments. Appl Environ Microbiol 55, 1472-1476.

Genthner, B. R. S., Price, W. A., II \& Pritchard, P. H. (1989b). Anaerobic degradation of chloroaromatic compounds in aquatic sediments under a variety of enrichment conditions. Appl Environ Microbiol 55, 1466-1471.

Gibson, S. A. \& Suflita, J. M. (1986). Extrapolation of biodegradation results to groundwater aquifers: reductive dehalogenation of aromatic compounds. Appl Environ Microbiol 52, 681-688.

Häggblom, M. M. \& Young, L. Y. (1990). Chlorophenol degradation coupled to sulfate reduction. Appl Environ Microbiol 56, 3255-3260.

Häggblom, M. M. \& Young, L. Y. (1995). Anaerobic degradation of halogenated phenols by sulfate-reducing consortia. Appl Environ Microbiol 61, 1546-1550.

Häggblom, M. M. \& Young, L. Y. (1999). Anaerobic degradation of 3-halobenzoates by a denitrifying bacterium. Arch Microbiol 171, 230-236.

Häggblom, M. M., Rivera, M. D. \& Young, L. Y. (1993). Influence of alternative electron acceptors on anaerobic biodegradability of chlorinated phenols and benzoic acids. Appl Environ Microbiol 59, 1162-1167.

Heider, J. \& Fuchs, G. (1997). Anaerobic metabolism of aromatic compounds. Eur J Biochem 243, 577-596.

Hoover, S. R. \& Porges, N. (1952). Assimilation of dairy wastes by activated sludge. II. The equation of synthesis and rate of oxygen utilization. Sewage Ind Wastes 24, 306-312.

Juteau, P., Beaudet, R., McSween, G., Lépine, F., Milot, S. \& Bisaillon, J.-G. (1995). Anaerobic biodegradation of pentachlorophenol by a methanogenic consortium. Appl Microbiol Biotechnol 44, 218-224.

Kazumi, J., Häggblom, M. M. \& Young, L. Y. (1995). Degradation of monochlorinated and nonchlorinated aromatic compounds under iron-reducing conditions. Appl Environ Microbiol 61, 4069-4073.

Kringstad, K. P. \& Lindström, K. (1984). Spent liquors from pulp bleaching. Environ Sci Technol 18, 236A-248A.

Madsen, T. \& Aamand, J. (1992). Anaerobic transformation and toxicity of trichlorophenols in a stable enrichment culture. Appl Environ Microbiol 58, 557-561.

Madsen, T. \& Licht, D. (1992). Isolation and characterization of an anaerobic chlorophenol-transforming bacterium. Appl Environ Microbiol 58, 2874-2878.

Mikesell, M. D. \& Boyd, S. A. (1986). Complete reductive dechlorination and mineralization of pentachlorophenol by anaerobic microorganisms. Appl Environ Microbiol 52, 861-865.
Mohn, W. W. \& Kennedy, K. J. (1992). Limited degradation of chlorophenols by anaerobic sludge granules. Appl Environ Microbiol 58, 2131-2136.

Nicholson, D. K., Woods, S. L., Istok, J. D. \& Peek, D. C. (1992). Reductive dechlorination of chlorophenols by a pentachlorophenol-acclimated methanogenic consortium. Appl Environ Microbiol 58, 2280-2286.

Nozawa, T. \& Maruyama, Y. (1988). Anaerobic metabolism of phthalate and other aromatic compounds by a denitrifying bacterium. J Bacteriol 170, 5778-5784.

Rabus, R. \& Widdel, F. (1995). Anaerobic degradation of ethylbenzene and other aromatic hydrocarbons by new denitrifying bacteria. Arch Microbiol 163, 96-103.

Rice, C. W. \& Tiedje, J. M. (1989). Regulation of nitrate assimilation by ammonium in soils and in isolated soil microorganisms. Soil Biol Biochem 21, 597-602.

Rockne, K. J., Chee-Sanford, J., Sanford, R. A., Hedlund, B. P., Staley, J. T. \& Strand, S. E. (2000). Anaerobic naphthalene degradation by microbial pure cultures under nitrate-reducing conditions. Appl Environ Microbiol 66, 1595-1601.

Sanford, R. A. \& Tiedje, J. M. (1997). Chlorophenol dechlorination and subsequent degradation in denitrifying microcosms fed low concentrations of nitrate. Biodegradation 7, 425-434.

Sanford, R. A., Cole, J. R., Löffler, F. E. \& Tiedje, J. M. (1996). Characterization of Desulfitobacterium chlororespirans sp. nov., which grows by coupling the oxidation of lactate to the reductive dechlorination of 3-chloro-4-hydroxybenzoate. Appl Environ Microbiol 62, 3800-3808.

van Schie, P. M. \& Young, L. Y. (1998). Isolation and characterization of phenol-degrading denitrifying bacteria. Appl Environ Microbiol 64, 2432-2438.

Takeuchi, R., Suwa, Y., Yamagishi, T. \& Yonezawa, Y. (2000). Anaerobic transformation of chlorophenols in methanogenic sludge unexposed to chlorophenols. Chemosphere 41, 1457-1462.

Utkin, I., Dalton, D. D. \& Wiegel, J. (1995). Specificity of reductive dehalogenation of substituted ortho-chlorophenols by Desulfitobacterium dehalogenans JW/IU-DC1. Appl Environ Microbiol 61, 346-351.

Valo, R., Kitunen, V., Salkinoja-Salonen, M. \& Räisänen, S. (1984). Chlorinated phenols as contaminants of soil and water in the vicinity of two Finnish sawmills. Chemosphere 13, 835-844.

Valo, R., Kitunen, V. \& Salkinoja-Salonen, M. S. (1985). Chlorinated phenols and their derivatives in soil and ground water around wood-preserving facilities in Finland. Wat Sci Tech 17, 1381-1384.

Widdel, F. \& Bak, F. (1992). Gram-negative mesophilic sulfatereducing bacteria,. In The Prokaryotes, 2nd edn, pp. 3352-3378. Edited by A. Balows and others. New York: Springer.

Woods, S. L., Ferguson, J. F. \& Benjamin, M. M. (1989). Characterization of chlorophenol and chloromethoxybenzene biodegradation during anaerobic treatment. Environ Sci Technol 23, 62-68.

Zhang, X. \& Wiegel, J. (1990). Sequential anaerobic degradation of 2,4-dichlorophenol in freshwater sediments. Appl Environ Microbiol 56, 1119-1127.

Received 21 May 2001; revised 27 July 2001; accepted 29 August 2001. 